\title{
Antibiotic treatment for acute otitis media: time to think again
}

\section{R.A.M.J. Damoiseaux}

T

he use of antibiotics in the treatment of acute otitis media remains a controversial area in medical practice. Clinical guidelines have been proposed, but practice patterns remain varied, ${ }^{1}$ reflecting the indecisiveness of existing recommendations with respect to withholding antibiotics, especially for children under 2 years of age. The Ontario Guidelines Advisory Committee, for example, advises using antibiotics to treat any symptomatic episode of acute otitis media. The guidelines of the American Academy of Pediatrics and the American Academy of Family Physicians recommend an observation period for children under 2 years of age only when the diagnosis is uncertain and symptoms are not severe. In many countries most episodes are still treated with antibiotics. ${ }^{1}$

In a recent issue of CMAF, Nicole Le Saux and colleagues ${ }^{2}$ report the results of a randomized controlled trial that compared routine antibiotic treatment of acute otitis media with a wait-and-see approach. Designed as a noninferiority trial, their study was unable to show that a waitand-see strategy was not inferior to the immediate use of antibiotics. In plain language, there was a difference between the 2 treatment arms that favoured the antibiotic group: an $8.6 \%$ (95\% confidence interval [CI] 3\%-14.8\%) improvement in clinical resolution at 2 weeks compared with the wait-and-see group. ${ }^{2}$ These results show only a moderate effect of antibiotics: 11 children would need to receive antibiotics immediately to prevent 1 failure, defined as the receipt of an antimicrobial within 14 days. Thus it is disappointing that Le Saux and colleagues restrict their conclusion to a call for further research to identify factors that could predict likelihood of success, when in fact their study adds to existing evidence that primary care physicians should be more restrictive with antibiotics as an initial treatment for acute otitis media.

Internationally, it is becoming increasingly accepted that antibiotics are not necessary for every episode of acute otitis media. ${ }^{3}$ The disadvantages of the abundant use of antibiotics for this common, mainly self-limiting disease are well known. The increased bacterial resistance to many commonly used antibiotics poses a serious threat to public health. ${ }^{4}$ Nor should we ignore the risks to the individual patient of an allergic reaction, gastrointestinal symptoms, or the potential disturbance of the nasopharyngeal flora. Although Le Saux and colleagues, like many other researchers, found no difference in the recurrence of otitis media in the first 3 months after antibiotic treatment, it is known that newly acquired carriage of bacterial pathogens is associated with a heightened risk of acute otitis media. ${ }^{5} \mathrm{In}$ accordance with these findings, in the long-term follow-up of our own randomized controlled trial comparing amoxicillin therapy with placebo in the treatment of acute otitis media, ${ }^{6}$ we found that $54 \%$ of children receiving placebo did not have another episode, versus $36 \%$ of those who received amoxicillin (adjusted odds ratio 2.7 [95\% CI 1.3-5.6]). ${ }^{7}$ Moreover, Little and colleagues have shown that the prescription of antibiotics increases the likelihood of their use in future illness. ${ }^{8}$

Although it seems prudent to administer antibiotics to children with severe symptoms of acute otitis media, it should still be noted that there is little evidence to support this practice, since many trials (including that by Le Saux and colleagues) excluded children who were severely ill. ${ }^{9} \mathrm{Le}$ Saux and colleagues' results suggest that antibiotics might be of particular benefit for children in whom the presence of middle ear fluid has been confirmed by tympanometry. However, this finding should be interpreted with caution, since the researchers do not mention the use of an interaction test to prove that the difference between the subgroups was statistically significant. ${ }^{10}$ Another study that suggested that children with acute otitis media with fever and vomiting have better outcomes with immediate antibiotic prescription had the same flaw: the numbers of the subgroups were small, and no interaction test was performed. ${ }^{11}$

Evidence-based guidelines can help clarify the clinical management of diseases when controversy exists. In the Netherlands, family practice guidelines recommend that acute otitis media in children 6 months of age and older be treated initially with analgesics only. The results of the second Dutch national survey of general practice showed that in $200150 \%$ of all presented episodes of acute otitis media were treated with antibiotics - a $65 \%$ increase over prescription rates in $1987 . .^{12}$ This may look as if practice in the Netherlands approaches that in United Kingdom and North America, where the majority of episodes of acute otitis media are treated with antibiotics. ${ }^{1}$ However, the increase in prescribing rates per 1000 people was only $30 \% .^{12} \mathrm{We}$ also need to interpret these numbers in light of the fact that most parents in the Netherlands have become acquainted with the "wait-and-see" approach, and hence it may be that only the more severely affected children are seen by a doctor. In an international comparative study Dutch children had the highest ratings in all severity measures. ${ }^{1}$

It is obvious that even with restrictive guidelines there will always be episodes of acute otitis media in which antibiotic therapy is indicated. Guidelines can never become rules to 
which everyone must adhere. But even if antibiotic prescription rates for acute otitis media were reduced to $50 \%$, this would help to mitigate the problem of antibiotic resistance. A Finnish study has shown that a reduction of $50 \%$ in antibiotic prescriptions resulted in a $50 \%$ reduction of resistant bacteria. ${ }^{13}$ Opponents of restrictive guidelines warn about the increased risk of acute mastoiditis. However, the potential increase is only 2 cases per 100000 person-years, and it is doubtful whether this countervails the adverse effects of the abundant use of antibiotics. ${ }^{14}$

This new study by Le Saux and colleagues should not be used as another argument to continue the present policy in many countries to treat most symptomatic episodes of acute otitis media with antibiotics. Although we should continue to look for factors that can predict the likelihood of success of antibiotic treatment, in the face of this further confirmation that antibiotic treatment has only a minor impact in acute otitis media, we should not delay in making existing guidelines more restrictive. As long as guidelines continue to advise physicians to treat almost every child with symptomatic otitis media immediately with antibiotics, or only children from 6 months until 2 years with such an episode, doctors will continue to prescribe antibiotics needlessly. The initial step in the treatment of uncomplicated cases in children from 6 months of age and older should be analgesics. Proper follow-up should be guaranteed in case deterioration occurs. If the child is severely ill or seems to be septic, than antibiotics should be started at the first contact. More restrictive guidelines for the use of antibiotics in acute otitis media will cause physicians to think more carefully about what is best for each patient. And this is what we are trained to do.

R.A.M.J. Damoiseaux is a general practitioner at General Practice "de Hof van Blom," Hattem, The Netherlands.

Competing interests: None declared.

\section{References}

1. Froom J, Culpepper L, Green LA, de Melker RA, Grob P, Heeren T, et al. A cross-national study of acute otitis media: risk factors, severity, and treatment at initial visit: report from the International Primary Care Network (IPCN) and the Ambulatory Sentinel Practice Network (ASPN). 7 Am Board Fam Pract 2001;14:406-17.

2. Le Saux N, Gaboury I, Baird M, Klassen TP, MacCormick J, Blanchard C, et al. A randomized double-blind controlled non-inferiority trial of placebo versus amoxicillin for clinically diagnosed acute otitis media in children 6 months to 5 years. CMA7 2005;172(3):335-41.

3. Rovers MM, Schilder AGM, Zielhuis GA, Rosenfeld RM. Otitis media. Lancet 2004;363:465-73

4. Cohen ML. Epidemiology of drug resistance: implications for a post-antimicrobial era. Science 1992;257:1050-5.

5. Faden H, Duffy L, Wasielewski R, Wolf J, Krystofik D, Tung Y. Relationship between nasopharyngeal colonisation and the development of otitis media in children. 7 Infect Dis 1997;175:1140-5

6. Damoiseaux RAMJ, van Balen FAM, Hoes AW, Verheij TJM, de Melker RA. Primary care based randomised, double blind trial of amoxicillin versus placebo for acute otitis media in children aged under 2 years. BMF 2000;320 $350-4$.

7. Damoiseaux RAMJ. Otitis media. Lancet 2004:363:1324.

8. Little P, Williamson I, Warner G, Gantley M, Kinmonth AL. Reattendance and complications in a randomised trial of prescribing strategies for sore throat: the medicalising effect of prescribing antibiotics. BM7 1997;315:350-2.

9. Bain J. Treatment of acute otitis media: are children entered in clinical trials representative? Br 7 Gen Pract 2001;51:132-3.

10. Assmann SF, Pocock SJ, Enos LE, Kasten LE. Subgroup analysis and other (mis)uses of baseline data in clinical trials. Lancet 2000;355:1064-9.

11. Little P, Gould C, Moore M, Warner G, Dunleavy J, Williamson I. Predic tors of poor outcome and benefits from antibiotics in children with acute otitis media: pragmatic randomised trial. BM7 2002;325:22-7.

12. Otters HBM, van der Wouden JC, Schellevis FG, van Suijlekom-Smit LWA Koes BW. Trends in prescribing antibiotics for children in Dutch general practice. 7 Antimicrob Chemother 2004;53:361-6.

13. Seppälä H, Klaukka T, Vuopio-Varkila J, Muotiala A, Helenius H, Lager K, et al. The effect of changes in the consumption of macrolide antibiotics on erythromycin resistance in group A Streptococci in Finland. $N$ Engl $7 \mathrm{Med}$ 1997;337:441-6.

14. Van Zuijlen DA, Schilder AG, van Balen FA, Hoes AW. National differences in incidence of acute mastoiditis: relationship to prescribing patterns of antibiotics for acute otitis media? Pediatr Infect Dis 7 2001;20:140-4.

Correspondence to: Dr. R.A.M.J. Damoiseaux, General Practice "de Hof van Blom," 8051 JT Hattem, The Netherlands; rdamoiseaux@hotmail.com

\section{P M I S C H E D U L E}

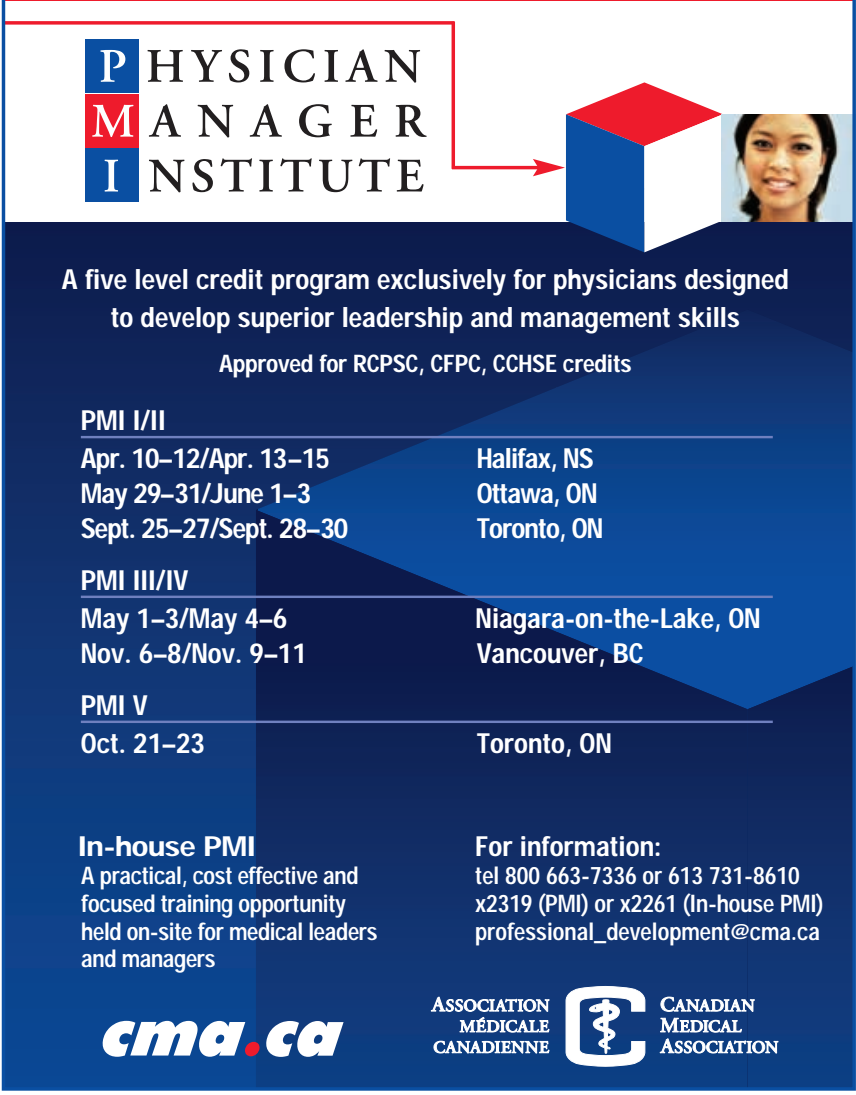

